\title{
ENDOTRACHEAL TUBE ETVIEW AS A TOOL FOR AIRWAY MANAGEMENT
}

\author{
Silvia Markic \\ Faculty of Medicine, University of Ljubljana, Slovenia, Ljubljana, Slovenia
}

Disaster Emerg Med J 2018; 3(4): 152-153

Sir,

I have read the article "The ETView tracheoscopic ventilation tube for trauma patient intubation" by Marcin Madziala published in the Disaster and Emergency Medicine Journal in issue 2018/3 [1]. In the study, the author points to the possibility of using the ETview in patients with suspected cervical spine injury damage and stabilized with the use of a cervical collar. Madziala showed that the nurses were able to perform endotracheal intubation with ETView with a higher efficacy (90.4\%) than standard Macintosh laryngoscope (34.6\%) after a short training. The results of the study also confirm the study by Gawlowski et al. [2].

Endotracheal intubation is a recognized method of airway management during cardiopulmonary resuscitation conditions, as evidenced, for example, by the European Resuscitation Council or the American Heart Association guidelines [3,4]. Currently, the golden standard is endotracheal intubation performed with the use of Macintosh laryngoscope [5]. It is problematic in the context of direct laryngoscopy that the effectiveness of this method of endotracheal intubation is insufficient. Therefore, it is necessary to search for alternative methods of airway management.

Sierzantowicz points to the possibility of intubation with ETView during cardiopulmonary resuscitation [6]. However, Umutoglu demonstrates that ETView might be a useful tool for airway management of tracheal injuries in anesthesiologists' armamentarium [7]. On the other hand, Barak fund that the ETView TVT facilitated surveillance of tube position by providing a clear high-qual- ity view of the carina, throughout percutaneous nephrolithotomy with several changes of patient position [8].

Thanks to its construction, the device provides continuous visualization from the distal end of the endotracheal tube, thanks to which it is possible to position the tube more precisely and place it in the trachea (Fig. 1).

ETview is used in prehospital conditions or in the emergency department. However, it also enables intraoperative repositioning of the endotracheal tube or bronchial blocker. Thanks to the built-in camera it is possible to introduce a bronchial blocker under constant image monitoring.

The study by Madziala is an important contribution to pre-hospital intubation, but the limitations of ETView should also be considered. The limitation of the ETView structure is the limited number of sizes, which in the case of single-lumen tubes are 7.0, 7.5- and 8.0-mm internal diameter, respectively. For

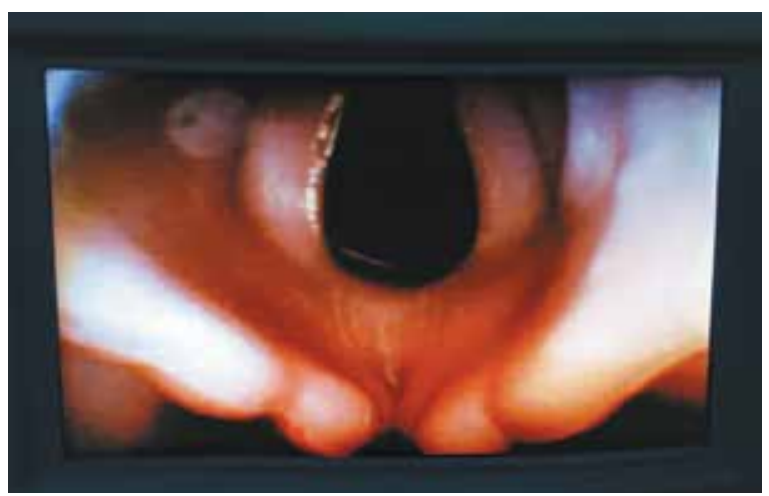

FIGURE 1. Image from the distal end of the ETView tube, during endotracheal intubation 
double-lumen tubes, the sizes shall be respectively: $35 \mathrm{Fr}, 37 \mathrm{Fr}, 39 \mathrm{Fr}$ and $41 \mathrm{Fr}$.

\section{REFERENCES:}

1. Madziała M. The ETView tracheoscopic ventilation tube for trauma patient intubation. Disaster and Emergency Medicine Journal. 2018; 3(2): 69-70, doi: 10.5603/demj.2018.0016.

2. Gawlowski P, Smereka J, Madziala M, et al. Comparison of the ETView Single Lumen and Macintosh laryngoscopes for endotracheal intubation in an airway manikin with immobilized cervical spine by novice paramedics: A randomized crossover manikin trial. Medicine (Baltimore). 2017; 96(16): e5873, doi: 10.1097/MD.0000000000005873, indexed in Pubmed: 28422820.

3. Link MS, Berkow LC, Kudenchuk PJ, et al. Part 7: Adult Advanced Cardiovascular Life Support: 2015 American Heart Association Guidelines Update for Cardiopulmonary Resuscitation and Emergency Cardiovascular Care. Circulation. 2015; 132(18 Suppl 2): 444-464, doi: 10.1161/CIR.0000000000000261, indexed in Pubmed: 26472995.
4. Szarpak L. Laryngoscopes for difficult airway scenarios: a comparison of the available devices. Expert Rev Med Devices. 2018; 15(9): 631-643, doi: 10.1080/17434440.2018.1511423, indexed in Pubmed: 30099914.

5. Szalast P, Smereka J, Ruetzler K, et al. Comparison of Airtraq ${ }^{\circledR}$ and Macintosh laryngoscope applied by nurses in manikins with normal and difficult airways: pilot data. Post N Med . 2018; 31(5): 248-253, doi: 10.25121/PNM.2018.31.5.248.

6. Sierzantowicz R, Dabrowska A, Dabrowski M, et al. ETView ${ }^{\circledR}$ video-tube versus Intubrite $\AA$ laryngoscope for endotracheal intubation during CPR. Am J Emerg Med. 2017; 35(9): 1367-1368, doi: 10.1016/j. ajem.2017.03.006, indexed in Pubmed: 28274710.

7. Umutoglu T, Bakan M, Topuz U, et al. Use of ETView Tracheoscopic Ventilation Tube ${ }^{\circledR}$ in airway management of a patient with tracheal injury. Minerva Anestesiol. 2014; 80(3): 398-399, indexed in Pubmed: 24226494.

8. Barak M, Putilov V, Meretyk S, et al. ETView tracheoscopic ventilation tube for surveillance after tube position in patients undergoing percutaneous nephrolithotomy. Br J Anaesth. 2010; 104(4): 501-504, doi: 10.1093/bja/aeq024, indexed in Pubmed: 20185518. 